\title{
Erratum: Ranking vs. Preference: A Comparative Study of Self-reporting
}

\author{
Georgios N. Yannakakis ${ }^{1}$ and John Hallam ${ }^{2}$ \\ ${ }^{1}$ Center for Computer Games Research, IT University of Copenhagen, Rued Langgaards Vej 7, \\ Copenhagen S, Denmark \\ yannakakis@itu.dk \\ ${ }^{2}$ Maersk Mc-Kinney Moller Institute, University of Southern Denmark, Campusvej 55, \\ Odense, Denmark \\ john@mmmi.sdu.dk \\ S. D'Mello et al. (Eds.): ACII 2011, Part I, LNCS 6974, pp. 437-446, 2011. \\ (C) Springer-Verlag Berlin Heidelberg 2011
}

DOI 10.1007/978-3-642-24600-5_65

In the original version the first word of the paper title was wrong. It should read:

"Rating vs. Preference: A Comparative Study of Self-reporting". 